\title{
Hesaplamalı Akışkanlar Dinamiği Yöntemi İle Emme Manifoldunun Tasarımı
}

\author{
Cihangir Kaplan ${ }^{1 *}$, Hasan Aydoğan² \\ $\mathbf{1}^{*}$ Kentpar Otomotiv, Konya, Türkiye, (ORCID: 0000-0002-6972-7959), kaplancihangir@gmail.com \\ ${ }^{2}$ Selçuk Üniversitesi, Teknoloji Fakültesi, Makine Mühendisliği Bölümü, Konya, Türkiye (ORCID: 0000-0003-1404-6352), haydogan@selcuk.edu.tr
}

(2nd International Conference on Access to Recent Advances in Engineering and Digitalization (ARACONF)-10-12 March 2021)

(DOI: 10.31590/ejosat.)

ATIF/REFERENCE: Kaplan, C. \& Aydoğan, H. (2021). Hesaplamalı Akışkanlar Dinamiği Yöntemi İle Emme Manifoldunun Tasarımı. Avrupa Bilim ve Teknoloji Dergisi, (24), Xx-Xx.

\section{Öz}

Günümüzde yüksek verimli bir motorun geliştirilmesi için çalışmalar yapılmaktadır. İçten yanmalı motorlardan birden fazla parçadan oluşmaktadır. Bu nedenle motor verimi bu parçalarla etkileşim halinde olmaktadır. Motorun verimini etkileyen en önemli faktörlerden birisi de silindir içerisine alınacak hava miktarıdır. Emme manifoldu ise silindir içerisine alınacak havanın ya da taze karışımının her silindir için eşit bir şekilde dağıtılmasını sağlamaktadır. Silindirlere gönderilecek olan hava karakteristiğini belirlemek için bazı yöntemler kullanılmaktadır. Bu yöntemlerden birisi ise hesaplamalı akışkanlar dinamiğidir. Bu çalışmada altı silindirli motor için emme manifoldu tasarımı gerçekleştirilmiştir. Literatür çalışmaları incelendiğinde emme manifold ile ilgili birçok çalışma görülmüştür. Bu yapılan çalışmalara istinaden farklı hava giriş port tasarımları gerçekleştirilmiştir. Tasarımları gerçekleştirilen emme manifoldları için hesaplamalı akışkan yöntemi kullanılmıştır. Çalışmadan elde edilen sonuçlar temel akış parametresi olan hız değişimleri cinsinden detaylı bir şekilde tartışılmıştır.

Anahtar Kelimeler: Emme manifoldu, Akış analizi, İçten yanmalı motorlar.

\section{Design of Intake Manifold with Computational Fluid Dynamics Method}

\begin{abstract}
Nowadays, studies are carried out to develop a high efficiency motor. It consists of multiple parts from internal combustion engines. Therefore, motor efficiency interacts with these parts. One of the most important factors affecting the efficiency of the engine is the amount of air to be taken into the cylinder. The intake manifold ensures that the air or fresh mixture to be taken into the cylinder is distributed equally for each cylinder. Some methods are used to determine the characteristics of the air to be sent to the cylinders. One of these methods is computational fluid dynamics. In this study, the design of the intake manifold for a six-cylinder engine was carried out. When the literature studies are examined, many studies on the intake manifold have been seen. Based on these studies, different air inlet port designs have been made. Computational fluid method was used for the designed intake manifolds. The results obtained from the study were discussed in detail in terms of velocity changes, which is the basic flow parameter.
\end{abstract}

Keywords: Air intake manifold, Flow analysis, Internal combustion engine.

\footnotetext{
*Sorumlu Yazar: kaplancihangir@gmail.com
} 


\section{Giriş}

Günlük hayatta içten yanmalı motorlar binek otomobiller, kamyonet, motorsiklet, uçak, gemi, tren gibi taşıma araçlarında yaygın olarak kullanılmaktadır. İçten yanmalı motorlar, birden fazla parçadan oluşan karmaşık yapıya sahip olmaktadır. İçten yanmalı bir motorun performansı birçok faktöre bağlı olarak değişmektedir. $\mathrm{Bu}$ faktörlerden en önemlisi silindirlerdeki yanmanın, ideal yanma koşullarını sağlamasıdır. İdeal yanma, silindir içinde reaksiyona giren hava ve yakıtın yeterli oranlarda karışması ile mümkündür. Hava-yakıt karışımını emme manifoldu yardımıyla silindirler içerisine taşınmasını sağlamaktadır. Bu nedenle motor tasarımcıları emme manifoldu dizaynına önem vermektedir (Shinde, 2014). Emme manifoldu hava-yakıt sistemi ile motor arasında bir tampon görevini üstlenmektedir. Emme manifold tasarımları, performans ile birlikte, motordaki konumu da göz önünde bulundurularak yapılmaktadır. Bu da önemli bir parametredir. Bunun sonucunda bazı seri üretim motorlarda düşük performanslı manifoldlar ile karşılaşabilmektedir (Ataman, 2017).

Tasarımdan sonra gelen en önemli bir parametre ise motor verimidir. Motorun verimini etkileyen en önemli faktörlerden biri de yanma odasına giren yakıtın tamamının yanmasını sağlanmasıdır. Bu durum yakıtın tamamı ile yanma reaksiyonuna girecek olan oksijenin, doğru miktarda ve doğru hız ve basınçlarda yanma odasına gönderilmesi ile sağlanır (Demircan ve ark.).

İçten yanmalı motorlarda kullanılacak emme manifoldları birbirinden farklı şekilde ve motora uygun çeşitlerde tasarlanmaktadır. Motor tiplerine bağlı olarak hava giriş portu, dolgu hacmi ve emme kanalları değişikliğe uğramaktadır. Ana hedef, silindirler içerisine alınacak havanın eşit olarak dağıtılması istenmektedir (Göçmen ve ark., 2020). Şekil 1'de emme manifoldu görülmektedir.

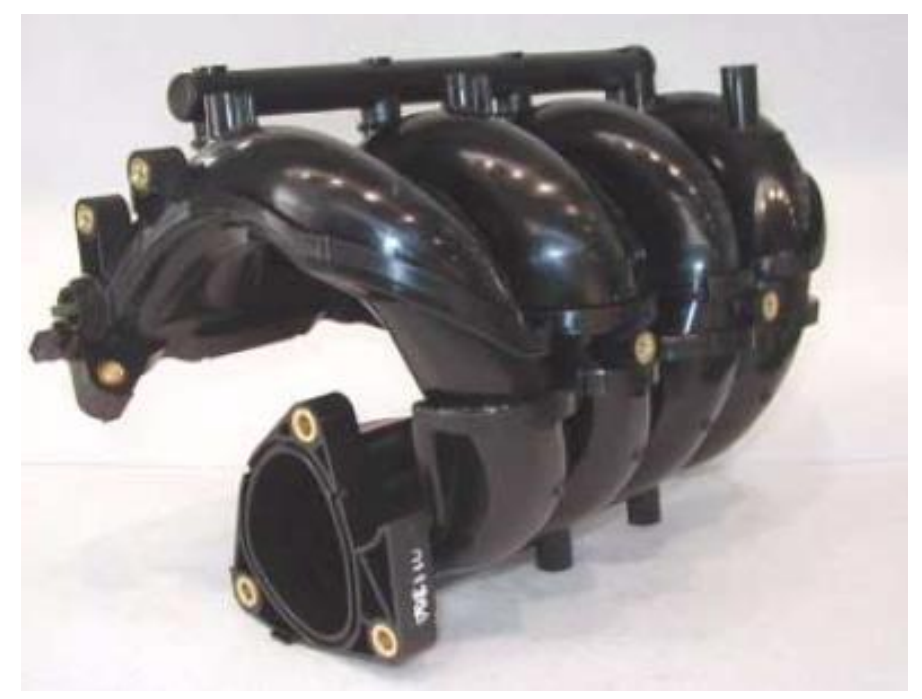

Şekil 1. Emme manifold görünümü

Emme manifoldu, yakıt ve hava karışımını motora taşımak için kullanılan bir motor parçasıdır. Emme manifoldu ram borusu (manifold girişi), plenum (dolgu hacmi) ve koşuculardan (borular) oluşur. Şekil 2'de gösterilmektedir.

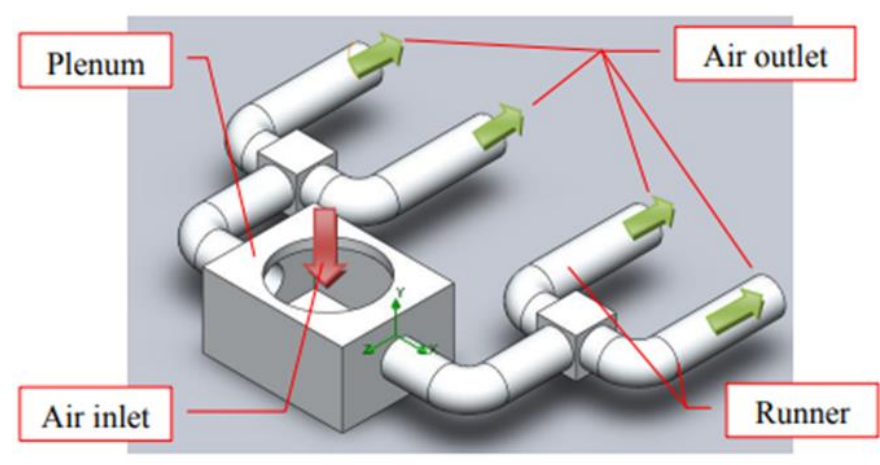

Şekil 2. Emme manifold bölümlerinin görünümü

Emme manifoldları taşıt motor performansı ve kirleticilerin emisyonu üzerinde yüksek etkileri vardır (Kannan ve ark., 2016). Hava, motor tarafindan oluşturulan vakum sayesinde emme manifold giriş kısmıyla plenuma girmektedir. Plenum yanma esnasında kullanılacak havayı depo olarak saklar ve daha sonra yanma havasını koşucular (boru) yardımıyla silindirler içerisine aktarmaktadir (Porter, 2009).

Tasarım sırasında problemleri en aza indirmek ve optimum bir emme manifoldu elde etmek için bazı parametrelere dikkat edilmesi gerekmektedir. Bunlar;

- Havanın tüm silindirlere eşit dağılımı

- Emme manifoldu koşucularda (boru) minimum direnç

- Üretim için uygun geometride emme manifoldu tasarımının gerçekleştirilmesi

- Emme manifoldundaki gereksiz türbülans ve girdap oluşumunun azaltılması

- Gaz kelebeği gövdesi konumunu doğru seçilmesi (Plenuma simetrik) (Safari ve ark., 2003).

Söz konusu çalışmamızda içten yanmalı motor için emme manifold ve hava giriş port tasarımları gerçekleştirilmiştir. Tasarımı gerçekleştirilen emme manifoldlar için hesaplamalı akışkan dinamiği yöntemi kullanılarak havanın silindirlere dağılımı incelenmiştir.

\section{Materyal ve Metot}

\subsection{Emme Manifold Tasarımı}

Bilgisayar destekli tasarım programlarının yardımıyla emme manifoldun tasarımları gerçekleştirilmektedir. Bu çalışmamızda Ford markalı altı silindirli bir motordan esinlenerek SolidWorks programıyla tasarımları yapılmıştır. $\mathrm{Bu}$ tasarımlardan yola çıkılarak ve çalışmamızın özgün yanı olan dört farklı hava giriş port tasarımı ile desteklenmiştir. Model-1 emme manidolunun hava giriş portu dolgu hacmine dik olarak tasarlanmıştır. Model2 emme manifoldu ise yan kısımlardan iki ayrı hava giriş kısmı ayarlanmıştır. Tasarımlar şekil 3'de gösterilmiştir. 

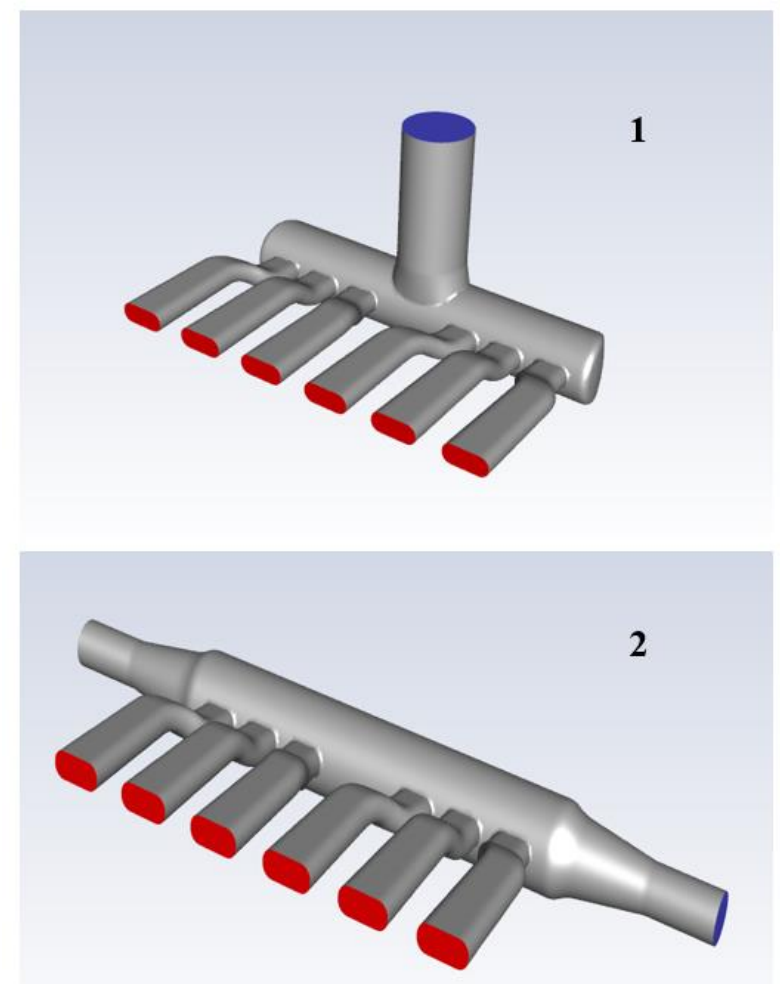

Şekil 3. Model-1 ve Model-2 numaralı emme manifold tasarım görünmü

Model-3 emme manifolduna tek girişli hava portu ve model4'de ise daha düz geniş bir şekilde tasarımları gerçekleştirilmiştir. Şekil 4'de gösterilmiştir.
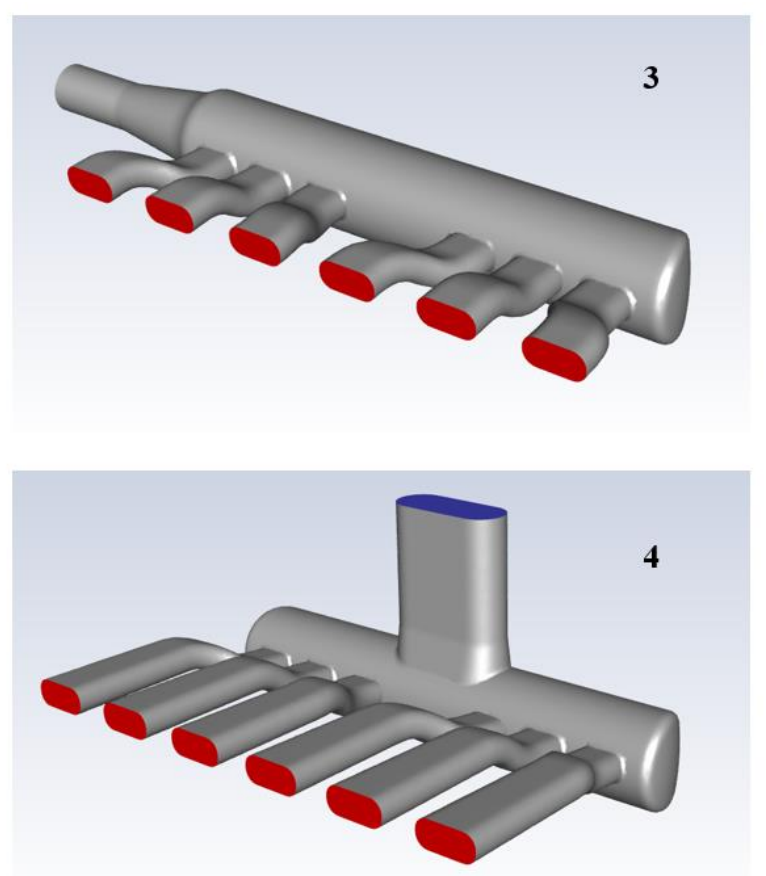

Şekil 4. Model-3 ve Model-4 numaralı emme manifold tasarım görünümü

\subsection{Emme Manifold Analizi}

Mühendislik hesaplama ve çalışmalarında, akışkan davranışının doğru tespit edilmesi oldukça önemlidir. Analitik yöntemlerle direkt olarak hesaplanamayan kompleks modellerde, 1Sı transferi, basınç kayıpları, akış hızları gibi verilerin nümerik yöntemlerle, parçanın tasarım aşamasında iken belirlenmesi, zaman ve maliyet açısından üreticiye önemli avantajlar sağlamaktadır.

Hesaplamalı Akışkanlar Dinamiği (HAD), ilgili alanda detaylı hesaplamaların yapılabildiği, akış alanı ve diğer fiziksel detayların gösterilebildiği, bilgisayar tabanlı bir mühendislik yöntemidir. HAD analizlerinin sonuçları, ürün tasarım sürecinde ürünün çalışmasını, oluşabilecek problemleri bilgisayar ortamında simüle etmeye ve ürün performansını optimize etmekte önemli faydalar sağlar.

Teorik ve deneysel çalışmalarla emme manifold koşucuları, dolgu hacmi gibi tasarım parametreleri değişikliklerinin getirdiği etkileri incelemek için emme manifold giriş hızı, basıncı sıcakları sabit tutularak çalışmalar yapılmaktadır. $\mathrm{Bu}$ çalışmamızda tasarımı gerçekleştirilen dört farklı hava giriş portlu emme manifoldları için giriş hızı, basınç ve sıcaklık gibi parametreler sabit tututlacaktır. Bu sayede, giriş portlarına bağlı olarak emme manifoldun performanslarını izleme firsatı bulunmuştur. Emme manifold geometrilerinin 3 boyutlu modellemeleri sonrasında çalışmamızda, ANSYS Fluent ticari yazılım kullanılarak analizleri gerçekleştirilmişstir. Bilindiği üzere sonlu elemanlar metodu ile yapılan çalışmalar; tasarım üzerinde meshlerin oluşturulması ve sınır şartları belirlenerek modeller kurulmaktadir.

Geometri üzerinde oluşturulan mesh (ağ) tipleri, boyutları ve kalitesi diğer parametrelerin sabit kalmasına rağmen elde edilebilecek sonuçları etkilemektedir.

Bu çalışmamızda yalnızca giriş portlarının geometrik ölçüleri ve giriş sayılarının emme manifoldundaki etkilerinin incelenmesi ve sonuçları etkilememesi için ANSYS üzerinden mesh (ağ) yapısı oluşturulmuştur. Emme manifold geometrilerinin mesh (ağ) yapısı şekil 5 ve 6'da gösterilmiştir.
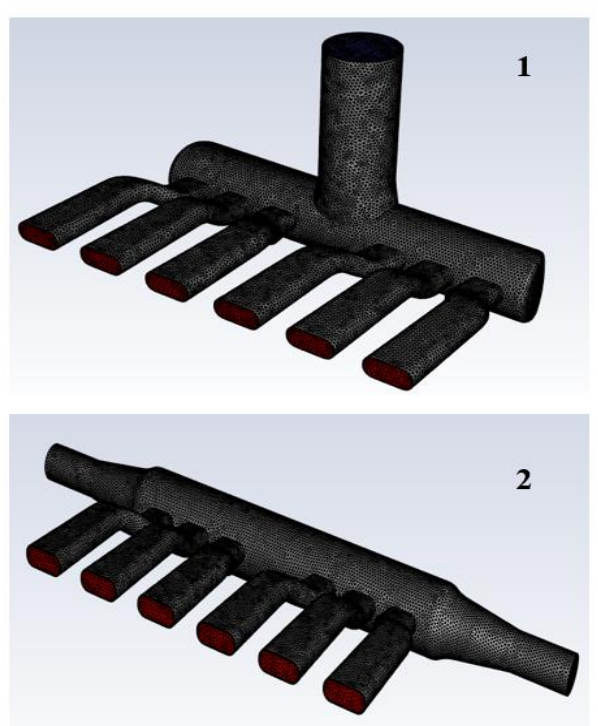

Şekil 5. 1 ve 2 numaralı emme manifoldun mesh (ağ) yapısı 


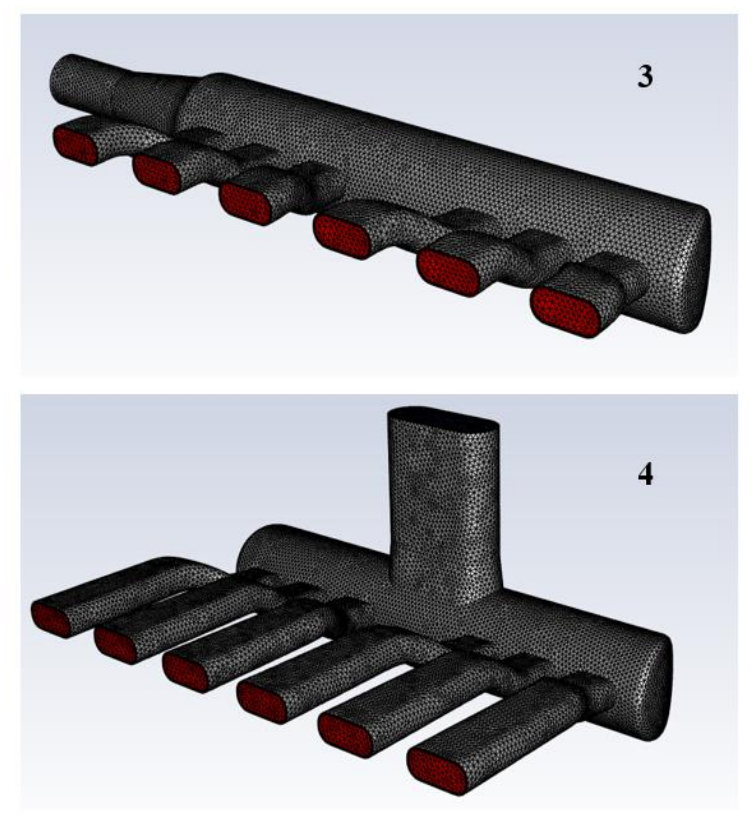

Şekil 6. 3 ve 4 numaralı emme manifoldun mesh (ağ) yapısı

Literatür çalışmaları incelendiğinde, emme manifoldlar için k- $\varepsilon$ türbülans modeli yaygın olarak kullanılmaktadır. Harlow ve Nakayama tarafından yapılan çalışmalar k- $\varepsilon$ modeline ilişkin ilk çalışmalardır. Kullanımı yaygın olması nedeniyle standart k- $\varepsilon$ olarak adlandırılmaktadır. Launder ve Sharma modele ait kapama katsayıları düzeltmişlerdir ve bu haliyle model araştırmacılar tarafindan kabul görmektedir. Bu çalışmadaki temel amacımız basınç, hız gibi akış parametreleri dikkate alınarak üç boyutlu, kararlı akışkan durumu için gerçekleştirilen sayısal simülasyon için türbülans modeli olarak k- $\varepsilon$ kullanılmıştır. Standart k- $\varepsilon$ modeli, iki denklemli türbülans modelleri arasında ekonomikliği ve pek çok olayında kabul edilebilir doğrulukta sonuç vermesi açısından yaygın olarak kullanılan yarı ampirik modeldir.

Tablo 1. Çalışma sınır şartları

\begin{tabular}{|l|c|}
\hline \multicolumn{1}{|c|}{ Veriler } & Değerler \\
\hline Hava giriş hızı & $37,5 \mathrm{~m} / \mathrm{sn}$ \\
\hline Hava giriş basıncı & $1 \mathrm{~atm}$ \\
\hline Hava çıkış basıncı & $1 \mathrm{~atm}$ \\
\hline Sıcaklık & $313 \mathrm{~K}$ \\
\hline Türbülans modeli & $\mathrm{k}-\varepsilon$ modeli \\
\hline Zaman modeli & Steady \\
\hline
\end{tabular}

Yukarıda tablo 1' de bahsedilen çalışma şartları ile analiz için hazırlık yapılmıştır. Analiz çözümlenmesinde steady state yani zamandan bağımsız bir çözümleme gerçekleştirilmiştir.

\section{Araştırma Sonuçları ve Tartışma}

Söz kousu çalışmamızda, altı silindirli bir motor için farklı hava giriş portlarına sahip emme manifold tasarımları gerçekleştirilmiştir. Analiz verilerini incelemek için örnek tasarım üzerinde emme manifold koşucuları (çıkışlar), dolgu hacmi ve giriş bölümleri şekil 7'de gösterilmiştir.

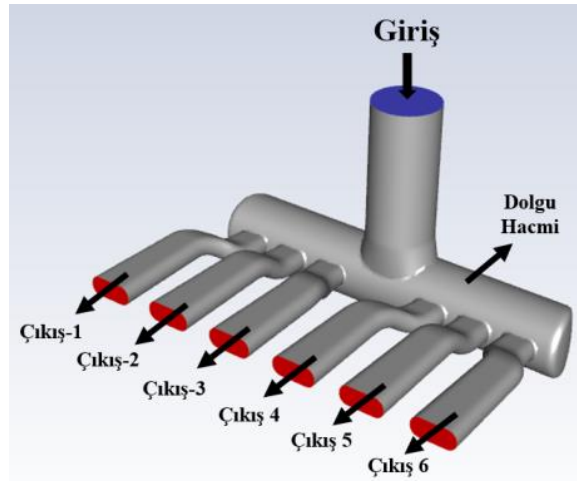

Şekil 7. Emme manifold koşucuların görünümü

Tasarımı gerçekleştirilen modeller için ANSYS-Fuent ticari yazılımı kullanılarak analizi yapılmış ve sayısal veriler elde edilmiştir.

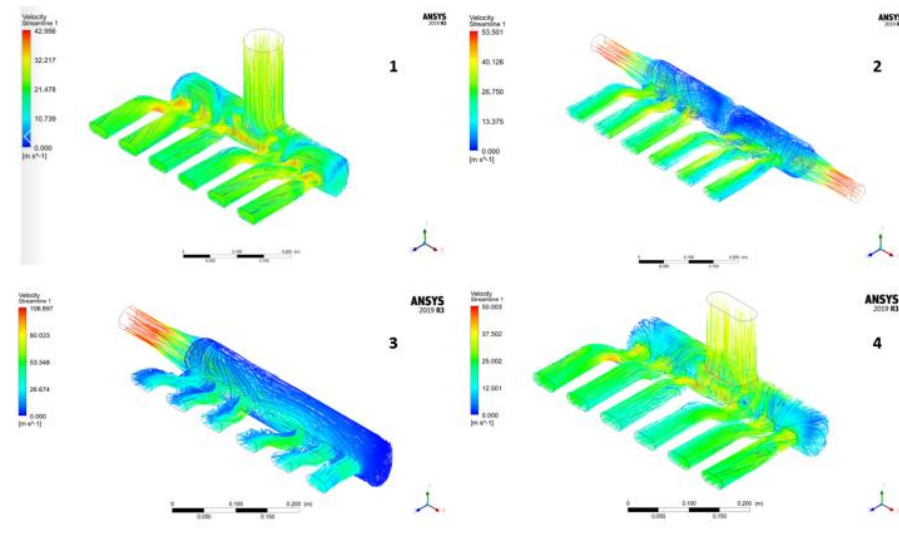

Şekil 8. Tasarım modellerine göre emme manifold hızları

Analiz sonucunda elde edilen emme manifold hız dağılımları bizlere alçak veya yüksek olduğunu bölgeler hakkında bilgiler vermektedir. Manifold giriş ve çıkışlarda kullanılan genişleme ya da daralma, dirsekler akışkanın düzgün akışını kesintiye uğratması kayıplara neden olacaktadır. Yukarıdaki resim incelendiğinde, modellerdeki koşucu ve hava giriş portlarında keskin köşelerden kaçınılmışıtır. Şekil 8'de gösterilen model-1 emme manifoldunun hız vektörleri ve tablo 2 'de ise modele ait maksimum hız verileri gösterilmiştir.

Tablo 2. Model-1 emme manifold hizları

\begin{tabular}{|l|l|}
\hline \multicolumn{2}{|c|}{ Model-1 } \\
\hline Çıkış-1 & $22,30 \mathrm{~m} / \mathrm{sn}$ \\
\hline Çıkış-2 & $22,19 \mathrm{~m} / \mathrm{sn}$ \\
\hline Çıkış-3 & $20,67 \mathrm{~m} / \mathrm{sn}$ \\
\hline Çıkış-4 & $20,60 \mathrm{~m} / \mathrm{sn}$ \\
\hline Çıkış-5 & $21,93 \mathrm{~m} / \mathrm{sn}$ \\
\hline Çıkış-6 & $22,22 \mathrm{~m} / \mathrm{sn}$ \\
\hline
\end{tabular}


Model-1 emme manifold çıkışları hızları incelendiğinde akış hızlarını birbirlerini yakın olduğu gözlemlenmiştir. Giriş bölümünde bahsediliği gibi emme manifollarından silindirlere alınacak hava eşit dağılmalıdır. Bu tasarım ile sağlanabilmektedir.

Tablo 3. Model-2 emme manifold hizları

\begin{tabular}{|c|c|}
\hline \multicolumn{2}{|c|}{ Model-2 } \\
\hline Çıkış-1 & $20,40 \mathrm{~m} / \mathrm{sn}$ \\
\hline Çıkış-2 & $21,85 \mathrm{~m} / \mathrm{sn}$ \\
\hline Çıkış-3 & $22,91 \mathrm{~m} / \mathrm{sn}$ \\
\hline Çıkış-4 & $22,58 \mathrm{~m} / \mathrm{sn}$ \\
\hline Çıkış-5 & $21,36 \mathrm{~m} / \mathrm{sn}$ \\
\hline Çıkış-6 & $20,19 \mathrm{~m} / \mathrm{sn}$ \\
\hline
\end{tabular}

Model-2 emme manifold analizinin hiz verileri tablo 3'de gösterilmiştir. Hız verileri incelendiğinde çıkış 1 ve 6 'da hızların düştüğü görülmektedir. Emme manifold tasarımı incelendiğinde iki taraftan hava girişinin olması ve havanın manifold koşucularına gelmeden dolgu hacminde akışın çarpması ile hız düşüşleri meydana gelmiştir.

Tablo 4. Model-3 emme manifold hızları

\begin{tabular}{|c|c|}
\hline \multicolumn{2}{|c|}{ Model-3 } \\
\hline Çıkış-1 & $17,41 \mathrm{~m} / \mathrm{sn}$ \\
\hline Çıkış-2 & $21,89 \mathrm{~m} / \mathrm{sn}$ \\
\hline Çıkış-3 & $25,87 \mathrm{~m} / \mathrm{sn}$ \\
\hline Çıkış-4 & $25,18 \mathrm{~m} / \mathrm{sn}$ \\
\hline Çıkış-5 & $27,35 \mathrm{~m} / \mathrm{sn}$ \\
\hline Çıkış-6 & $28,59 \mathrm{~m} / \mathrm{sn}$ \\
\hline
\end{tabular}

Model-3 hız verileri tablo 4'de gösterilmiştir. Akış hızları incelendiğinde çıkış-1 hızının diğer koşuculara göre daha az ve çıkış-6 ise yüksek hız gözlenmiştir. Giriş portuna yakın olan koşucu tarafında basınç kaybı meydana gelmiştir. Basınç kaybının nedeni akış dolgu hacminden koşuculara iletilmesi esnasında meydana gelmektedir. Dolgu hacmi yaşanan yansımalar ve koşucu (boru) duvarına çarpması hız kayıplarını meydana getirmektedir. Çıkış-6 ise akışkan havada kayıplar yaşanmaması ve daha fazla hava çekmesi nedeniyle hız artışına sebebiyet vermiştir.

Tablo 5. Model-4 emme manifold hizları

\begin{tabular}{|c|c|}
\hline \multicolumn{2}{|c|}{ Model-4 } \\
\hline Çıkış-1 & $23,50 \mathrm{~m} / \mathrm{sn}$ \\
\hline Çıkış-2 & $22,10 \mathrm{~m} / \mathrm{sn}$ \\
\hline Çıkış-3 & $19,02 \mathrm{~m} / \mathrm{sn}$ \\
\hline Çıkış-4 & $19,10 \mathrm{~m} / \mathrm{sn}$ \\
\hline Çıkış-5 & $22,05 \mathrm{~m} / \mathrm{sn}$ \\
\hline Çıkış-6 & $23,47 \mathrm{~m} / \mathrm{sn}$ \\
\hline
\end{tabular}

Model-4 analiz verileri ise tablo 5'de gösterilmiştir. Bu emme manifold incelendiğinde çıkış 3 ve 4'de hız düşüşleri meydana gelmiştir. Manifold girişinin geniş olması nedeniyle türbülans oluşmuştur. Buda istenilen hava akış hareketinin oluşmasını engellemiştir.

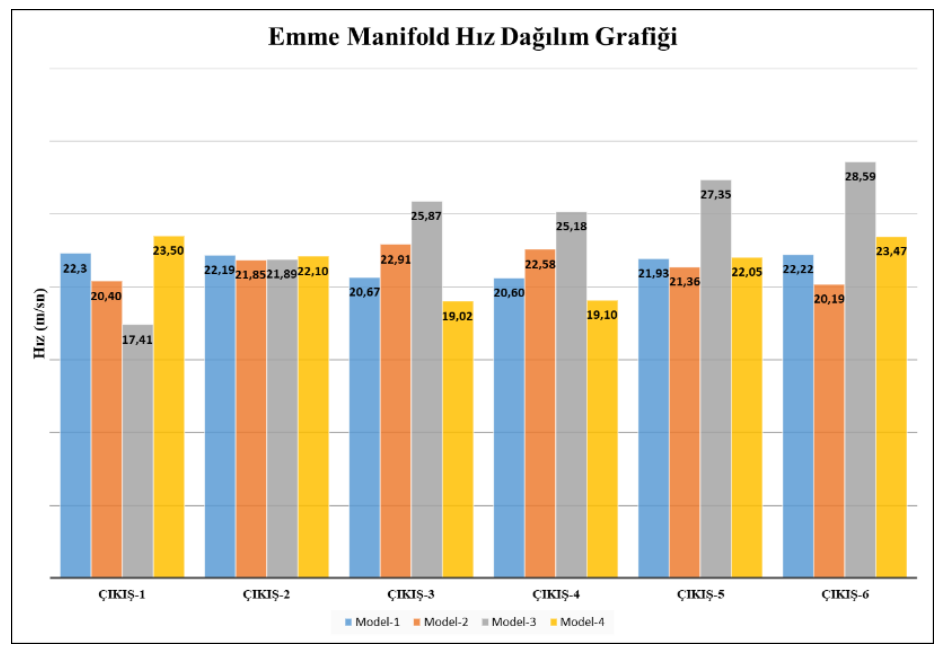

Şekil 9. Analiz sonuçlarına göre emme manifoldu dağılım grafiği

İçten yanmalı motorlarda silindirler içerisine alınacak hava yada hava-yakıt karışımı homojen ve eşit bir şekilde emme manifold tarafından taşınması sağlanmalıdır. Yukarıdaki grafik incelendiğinde model-1 tasarımı daha uygun olduğu gözükmektedir.

\section{Sonuç}

Bu çalışmada, 6 silindirli içten yanmalı motor için faklı hava portlarına sahip emme manifold tasarımları gerçekleştirilmiştir. Tasarımı yapılan emme manifoldlar hava akışının karakteristeğini belirlemede ise hesaplamalı akışkanlar yöntemi kullanılarak sayısal incelemeler yapılmıştır. Analizler aşağıda maddeler belirtilmiştir. Bunlar;

- Emme manifold tasarımında hava giriş portunun genişliği ve şekli havanın akışı hızını etkilediği görülmüştür.

- Emme manifold koşucuların tasarımında dirsek, köşe ve daralmaların olması basınç düşüşlerine meydana getirdiği tepit edilmiştir.

- Model-1 tasarımı incelendiğinde silindir içerisine alınacak hava daha eşit bir şekilde gönderileceği görülmüştür.

- Model-3 tasarımı incelendiğinde çıkış-1 (koşucu)'de hız çok düşük olduğu çıkış-6 (koşucu)'da ise akış hızı çok yüksek olduğu tespit edilmiştir. Bunun nedeni plenum içerisindeki yansımalar hız kayıplarına sebebiyet vermiştir.

\section{Kaynakça}

Shinde, P. A. (2014). Research and optimization of intake restrictor for Formula SAE car engine. International Journal of Scientific and Research Publications, 4(4), 1. 
Ataman, T. (2017). Farklı Tasarımlardaki Emme Manifoldlarının Akış Analizlerinin Yapılarak En Uygun Tasarımın Belirlenmesi Karabük Üniversitesi Fen Bilimleri Enstitüsü.

Demircan, T., Polat, Z. E., \& Polat, H. T. (2017). İçten Yanmalı Bir Motorun Emme Manifoldunun Hesaplamalı Akışkanlar Dinamiği (HAD) ile Tasarımı.

Göçmen, K., \& Soyhan, H. S. (2020). An intake manifold geometry for enhancement of pressure drop in a diesel engine. Fuel, 261, 116193.

Porter, M. (2009). Intake manifold design using computational fluid dynamics. The UNSW Canberra at ADFA Journal of Undergraduate Engineering Research, 1(2), 31.

Kannan, C. R., \& Jose, S. S. H. (2016). CFD Analysis of Plenum Chamber in Intake Manifold of a Multi Cylinder SI EngineA. IJIRST-International Journal for Innovative Research in Science \& Technology, 2, 179-83.

Safari, M., Ghamari, M., \& Nasiritosi, A. (2003). Intake manifold optimization by using 3-D CFD analysis (No. 2003-32-0073). SAE Technical Paper. 